\title{
Zeolite-encapsulated 2-(o-aminophenyl)benzimidazole complexes: synthesis, characterization and catalytic activity
}

\author{
B. P. Nethravathi • K. N. Mahendra • \\ K. Rama Krishna Reddy
}

Published online: 12 May 2010

(C) Springer Science+Business Media, LLC 2010

\begin{abstract}
Cobalt(II), copper(II) and zinc(II) complexes of 2-(o-aminophenyl)benzimidazole (AmPhBzlH) encapsulated in the super cages of zeolite-Y and ZSM-5 have been synthesized and characterized by spectroscopic studies (IR, UV/visible, EPR), elemental analyses, thermal studies and X-ray diffraction patterns. The catalytic activity of encapsulated complexes was investigated for the hydroxylation of phenol using $30 \% \mathrm{H}_{2} \mathrm{O}_{2}$ as an oxidant. Under optimized reaction conditions, the hydroxylation of phenol yielded catechol and hydroquinone as the major products. All catalysts show good selectivity for diphenol products. A maximum conversion of phenol was obtained with $[\mathrm{Cu}(\mathrm{AmPhBzlH})]-\mathrm{Y}$ as the catalyst. The results showed that conversion of phenol varies in the order $[\mathrm{Cu}(\mathrm{AmP}-$ $\mathrm{hBzlH})]-\mathrm{Y}>[\mathrm{Cu}(\mathrm{AmPhBzlH})]-\mathrm{ZSM}-5>[\mathrm{Zn}(\mathrm{AmPhBzlH})]-\mathrm{Y}$ $>[\mathrm{Co}(\mathrm{AmPhBzlH})]-\mathrm{Y}>[\mathrm{Zn}(\mathrm{AmPhBzlH})]-\mathrm{ZSM}-5>[\mathrm{Co}$ $($ AmPhBzlH)]-ZSM-5 after $6 \mathrm{~h}$ of reaction time. Test for the recyclability of the reaction was also carried out and the results indicate their recyclability.
\end{abstract}

Keywords Encapsulation - Zeolite-Y · ZSM-5 ·

Hydrogen peroxide decomposition - Oxidation of phenol . Catechol and hydroquinone formation

\section{Introduction}

Considerable attention is being paid in recent years for the study of heterogenization of homogeneous catalysis. Heterogenization is achieved either by encapsulating the

B. P. Nethravathi · K. N. Mahendra $(\bowtie) \cdot$ K. R. K. Reddy

Department of Studies in Chemistry, Central College Campus,

Bangalore University, Bangalore 560001, India

e-mail: knmahendra@gmail.com metal complex inside the nanopores of zeolites or by anchoring them to inert supports [1]. The encapsulation approach is convenient and ideal because the complex, once formed inside the cages of the zeolite, is too large to diffuse out and is not lost in the liquid phase during the reaction. These encapsulated metal complexes offer several advantages in catalytic reactions due to their reaction ruggedness, protection against deactivation by dimer and cluster formation during catalysis and ease of separation from the reaction products. For example, mono and polynuclear carbonyl compounds of $\mathrm{Rh}$ and $\mathrm{Ir}$ have been entrapped in zeolite for vapour phase carbonylation reaction [2]. The $\mathrm{Pd}($ salen) complex encapsulated zeolite has been an active catalyst for selective hydrogenation of hex1-ene. They have more applications in the synthesis of fine chemicals and are being used in various types of catalytic reactions such as oxidation, alkylation and dehydrogenation [3-6] to produce major industrial products.

These encapsulated metal complexes in zeolites played considerable role in the hydroxylation of phenol using simple oxidants such as molecular oxygen and $\mathrm{H}_{2} \mathrm{O}_{2}$ [7-11]. About $72 \%$ selectivity towards the formation of catechol has been reported using 2-methyl benzimidazole complexes of $\mathrm{Cu}(\mathrm{II})$ encapsulated in zeolite-Y [12].

The major commercial process for the oxidation of phenol uses only zeolite-based catalyst TS-1 [13]. Over the past decade lot of research has been conducted in selective oxidation of organic functional groups with such reagents. However, liquid-phase oxidations with molecular oxygen are radical chain processes, and the intermediate alkylperoxy and alkoxy radicals are largely indiscriminate in their reactivity. Selective oxidation is normally observed with relatively small molecules containing one reactive group. Although molecular oxygen is a relatively cheap oxidant with limited waste problems, its scope is usually 
Scheme 1 Structure of 2-(o-aminophenyl) benzimidazole $(\mathrm{AmPhBzlH})$

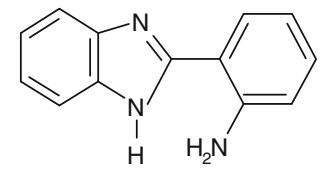

limited to a small number of simple petrochemicals. The economics of fine chemical and pharmaceutical production, in contrast, allow a broader range of primary oxidants to be employed. Though hydrogen peroxide is more expensive than oxygen, it can be the oxidant of choice because of its simplicity of operation, i.e. in fine chemical and pharmaceutical use, the total cost of equipment and raw material may be lower for oxidation employing hydrogen peroxide over oxygen [14].

So, based on the above discussion, the need for cleaner processes, many new and interesting technologies are emerging, especially in fine chemicals where high selectivity to the desired product is crucial. Therefore, the design of novel heterogeneous liquid-phase oxidations development technologies are gaining importance in the enatioselective oxidations and in different organic transformations.

In this work, studies on the synthesis and characterization of zeolite Y and ZSM-5 encapsulated complexes of $\mathrm{Co}(\mathrm{II}), \mathrm{Cu}(\mathrm{II})$ and $\mathrm{Zn}$ (II) with 2-(o-aminophenyl)benzimidazole $(\mathrm{AmPhBzlH})$ ligand are presented. The structure of the ligand is shown in Scheme 1. Applications of these complexes for hydroxylation of phenol were studied and the results of these studies are discussed.

\section{Experimental}

\subsection{Materials}

Protonated form of zeolite $\mathrm{Y}$ [H-Y] and ZSM-5 [H-ZSM-5] were purchased from Sud-Chemie, Mumbai. L R-Grade solvents used were purified according to the literature method [15]. Analytical grade cobalt chloride, copper nitrate, zinc nitrate, phenol and 30\% hydrogen peroxide purchased from Merck were used as such. 2-(o-aminophenyl)benzimidazole was prepared according to the literature method [16].

\subsection{Physicochemical characterization}

The metal content was estimated using Perkin-Elmer model ICP-AES instrument. The surface areas of the zeolite samples were determined by nitrogen adsorption at liquid nitrogen temperature by BET method [17] on a NOVA-1000 Ver. 3.70 instrument. Powder X-ray diffraction patterns of zeolite HY, H-ZSM-5 and the zeolite encapsulated complexes were recorded using Philips
X'Pert diffractometer using $\mathrm{CuK}_{\alpha}(\lambda=0.15405 \mathrm{~nm})$ target with nickel filter. Thermogravimetric analysis was recorded on a NETZSCH STA 409 PG/PC under nitrogen atmosphere for the encapsulated complex with the heating rate of $10{ }^{\circ} \mathrm{C} / \mathrm{min}$ from 30 to $800{ }^{\circ} \mathrm{C}$. The morphology of the sample was examined using Philips scanning electron microscopy. Infrared spectra of the ligand, simple complex and supported complexes in the region 4,000 to $400 \mathrm{~cm}^{-1}$ were recorded as $\mathrm{KBr}$ pellet on a FTIR-8400S Shimadzu spectrophotometer. The diffuse reflectance spectra were recorded at room temperature in the range $200-800 \mathrm{~nm}$ using $\mathrm{BaSO}_{4}$ as reference on a Shimadzu UV-Visible-NIR model UV-3101P instrument. The X-band EPR spectra of powdered samples of zeolite encapsulated $\mathrm{Cu}$ (II) complexes were recorded at room temperature on a VARIAN E-112 ESR spectrometer and the $\mathrm{g}$ values were estimated relative to tetracyanoethylene (TCNE, $g=2.0027$ ). Shimadzu 14B gas chromatograph fitted with FID detector connected with BP-5 capillary column was used to analyze the reaction products of the catalytic activity studies.

\subsection{Preparation of complexes}

Protonated form of zeolite Y (H-Y) or H-ZSM-5 (5 g) sample was stirred in a $100 \mathrm{~mL}$ aqueous solution of the respective metal salt. The mixture was refluxed with stirring for $12 \mathrm{~h}$ on an oil bath. It was filtered and washed with water till the washings were free from metal ions and then dried in an oven at $150{ }^{\circ} \mathrm{C}$ for $24 \mathrm{~h}$. This metal exchanged zeolite was treated with 2-(o-aminophenyl)benzimidazole in acetone and then refluxed with stirring for $24 \mathrm{~h}$ on an oil bath. The reaction mixture was filtered, washed with DMF and then with acetone using Soxhlet apparatus to remove any unreacted ligand and the metal complex adsorbed on the zeolite surface. The resulting solution was treated with aqueous $0.01 \mathrm{M} \mathrm{NaCl}$ with stirring for $15 \mathrm{~h}$ to allow exchange of uncomplexed metal ions with sodium ions. The zeolite encapsulated complex was then filtered, washed with distilled water to remove any chloride ions present and dried at $150{ }^{\circ} \mathrm{C}$ for $24 \mathrm{~h}$.

\subsection{Catalytic activity measurements}

\subsubsection{Decomposition of $\mathrm{H}_{2} \mathrm{O}_{2}$}

An aqueous solution of $30 \% \mathrm{H}_{2} \mathrm{O}_{2}(4 \mathrm{~mL})$ was added to $2 \mathrm{mmol}$ catalyst and it was stirred for $1-2 \mathrm{~h}$ at room temperature. The catalyst was then filtered and washed with distilled water. The filtrate containing partially decomposed $\mathrm{H}_{2} \mathrm{O}_{2}$ and the washings were collected in a $250 \mathrm{~mL}$ volumetric flask, and then made up to the mark with distilled water. Then $10 \mathrm{~mL}$ of this solution was 
titrated against a standard $\mathrm{KMnO}_{4}$ solution to estimate the unreacted $\mathrm{H}_{2} \mathrm{O}_{2}$ [18].

\subsubsection{Hydroxylation of phenol}

The reactions were carried out in a $50 \mathrm{~mL}$ double-necked round bottom flask fitted with a water cooled condenser. In a typical reaction, phenol $(2.35 \mathrm{~g}, 0.025 \mathrm{~mol})$ and $30 \%$ aqueous $\mathrm{H}_{2} \mathrm{O}_{2}(4 \mathrm{~mL}, 0.05 \mathrm{~mol})$ were dissolved in $2 \mathrm{~mL}$ of acetonitrile and the reaction mixture was heated on an oil bath at $80{ }^{\circ} \mathrm{C}$ with continuous stirring. Then $6 \mathrm{mmol}$ of the catalyst was added and the reaction was considered to have begin. Aliquots were drawn from the reaction mixture at regular intervals for analysis using a gas chromatograph.

\section{Results and discussion}

\subsection{Synthesis and characterization of catalysts}

Synthesis of the metal complexes encapsulated in the zeolite cages of H-Y and H-ZSM-5 was carried out by the flexible ligand method [19]. The metal content in the encapsulated complex was determined by using the ICP instrument. The analysis of metal content along with the colour of the complexes and the surface area measurements is presented in Table 1.

The metal content is low. All the metal ions present seem to be complexed. Good catalytic activity can be the result of low metal ion concentration with high dispersion. To compare the properties of the neat with encapsulated complexes, the neat complexes of $\mathrm{Co}$ (II), $\mathrm{Cu}$ (II) and $\mathrm{Zn}$ (II) with AmPhBzlH were also prepared and characterized by various physicochemical techniques. The analytical data obtained were in good agreement with the data available in literature [20].
The encapsulations of $\mathrm{Co}(\mathrm{AmPhBzlH}), \mathrm{Cu}(\mathrm{AmPhBzlH})$ and $\mathrm{Zn}(\mathrm{AmPhBzlH})$ complexes inside the zeolite cavity is indicated by the lowering of surface area and pore volume. The surface area decreases $13.5,33.3$ and $10.1 \%$ for $\mathrm{Co}, \mathrm{Cu}$ and $\mathrm{Zn}$ encapsulated zeolite $\mathrm{Y}$ complexes, respectively. Similarly, a decrease of 48.2, 67.7 and $21.5 \%$ was observed for $\mathrm{Co}, \mathrm{Cu}$ and $\mathrm{Zn}$ encapsulated ZSM-5 zeolite complexes, respectively. The significant reduction in surface area and pore volume as a result of encapsulation of the complexes within the zeolite pores is due to the blocking of the pores by the formation of the metal complexes [21]. The decrease in surface area values suggests the formation of metal complexes inside the zeolite cages.

\subsection{Thermogravimetric analysis}

Thermal stability of the encapsulated complex was studied using TGA and DTG. Representative TGA and DTG curves of the $[\mathrm{Cu}(\mathrm{AmPhBzlH})]-\mathrm{Y}$ complex are shown in Fig. 1. The thermogravimetric analysis data for all the complexes are presented in Table 2.

Thermogravimetric analysis provides an approximate idea about the decomposition temperature of the supported complexes. All the encapsulated complexes show almost similar decomposition patterns. The weight loss of the encapsulated complexes occurs in three steps in the temperature range of $36-700{ }^{\circ} \mathrm{C}$. The first weight loss which starts around $40{ }^{\circ} \mathrm{C}$ indicates the loss of free water molecules in the zeolite cages. The second stage weight loss step begins after the first step which is probably due to the water molecules and chloride ions associated with the complex. As these catalysts were treated with aqueous $\mathrm{NaCl}$, the presence of $\mathrm{Cl}^{-}$counter ion is expected in all cases [22]. The third step which starts immediately after the second step having a wider temperature range is due to the decomposition of ligands. A very small weight

Table 1 Percentage of metal, colour and the surface area measurement data

\begin{tabular}{|c|c|c|c|c|c|}
\hline Sl. No. & Compound & Colour & Metal (wt\%) & $\mathrm{S}_{\mathrm{BET}}\left(\mathrm{m}^{2} / \mathrm{g}\right)^{\mathrm{a}}$ & Pore volume $(\mathrm{cc} / \mathrm{g})^{\mathrm{b}}$ \\
\hline 1 & $\mathrm{H}-\mathrm{Z}-\mathrm{Y}^{\mathrm{c}}$ & White & - & 25.8 & 0.105 \\
\hline 2 & $\mathrm{H}-\mathrm{ZSM}-5^{\mathrm{d}}$ & White & - & 258.7 & 0.179 \\
\hline 3 & {$[\mathrm{Co}(\mathrm{AmPhBzlH})]-\mathrm{Y}$} & Light pink & 0.662 & 22.31 & 0.092 \\
\hline 4 & {$[\mathrm{Co}(\mathrm{AmPhBzlH})]-\mathrm{ZSM}-5$} & Light pink & 0.057 & 134.1 & 0.112 \\
\hline 5 & {$[\mathrm{Cu}(\mathrm{AmPhBzlH})]-\mathrm{Y}$} & Brown & 2.043 & 17.22 & 0.042 \\
\hline 6 & {$[\mathrm{Cu}(\mathrm{AmPhBzlH})]-\mathrm{ZSM}-5$} & Light brown & 0.052 & 83.52 & 0.119 \\
\hline 7 & {$[\mathrm{Zn}(\mathrm{AmPhBzlH})]-\mathrm{Y}$} & Yellow & 1.755 & 23.20 & 0.059 \\
\hline 8 & {$[\mathrm{Zn}(\mathrm{AmPhBzlH})]-\mathrm{ZSM}-5$} & Light yellow & 0.207 & 203.18 & 0.171 \\
\hline
\end{tabular}

${ }^{a} \mathrm{~S}_{\mathrm{BET}}$ - specific surface area measured by BET method

b Pore volume calculated from $\mathrm{N}_{2}$ desorption by the BJH method

${ }^{\mathrm{c}} \mathrm{H}-\mathrm{Z}-\mathrm{Y}$ and ${ }^{\mathrm{d}} \mathrm{H}-\mathrm{ZSM}-5$ - protonated form of zeolite-Y and ZSM-5 


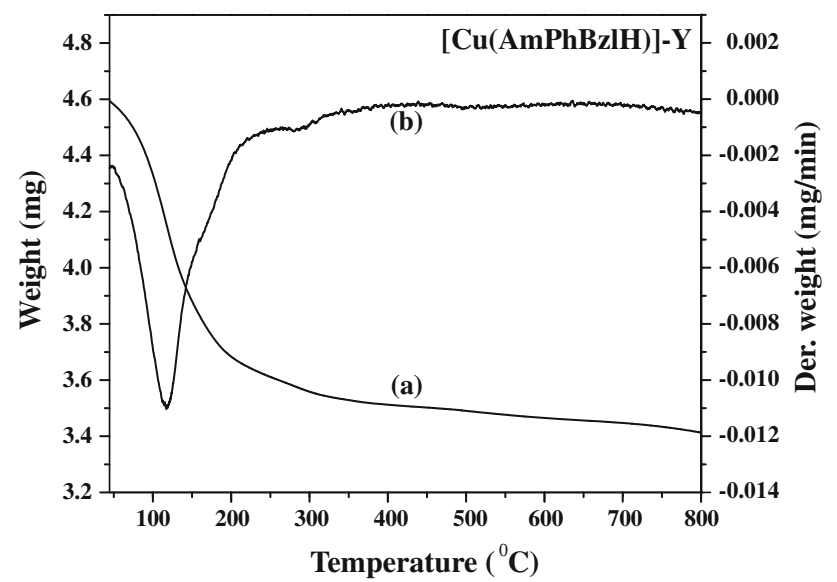

Fig. 1 (a) TGA and (b) DTG curves of $[\mathrm{Cu}(\mathrm{AmPhBzlH})]-\mathrm{Y}$

percentage loss indicates the insertion of only small amount of metal complexes in the zeolite-Y matrix. This is in agreement with the low metal content as estimated by the ICP instrument. The destruction of zeolite cage is expected to occur after $800{ }^{\circ} \mathrm{C}$.

\subsection{Powder X-ray diffraction studies}

The powder X-ray diffraction patterns of H-Y, H-ZSM-5 and the encapsulated complexes were recorded at $2 \theta$ values of $5-80^{\circ}$. Essentially very similar patterns are formed for the encapsulated complexes as compared to the starting zeolite $\mathrm{H}-\mathrm{Y}$ and H-ZSM-5, though slight changes in the intensity of the bands are seen. These observations indicate that the crystalline nature of the zeolite is retained even after the encapsulation of the complex. No new peaks were detected in the XRD patterns of the encapsulated complex possibly due to the presence of low content of the metal complexes.

\subsection{Infrared spectral studies}

The infrared spectral data of the ligand and complexes in Table 3 reveal the co-ordination of the ligand to the metal ion. 2-(o-aminophenyl)benzimidazole shows two bands, one at 3,376 and another split band at 3,175 and $3,135 \mathrm{~cm}^{-1}$. The former may be assigned to the $v_{\mathrm{N}-\mathrm{H}}$ of $\mathrm{NH}_{2}$ of the phenyl ring and the latter to the $v_{\mathrm{N}-\mathrm{H}}$ of the benzimidazole group. The $\mathrm{C}=\mathrm{N}\left(\right.$ and $v_{\mathrm{C}=\mathrm{C}}$ ) stretch and $\mathrm{NH}_{2}$ inplane bending modes are observed at 1,637 and $1,615 \mathrm{~cm}^{-1}$, respectively. The benzimidazole NH inplane bending is probably assignable at $1,586 \mathrm{~cm}^{-1}$. The ortho substituted phenyl group shows ring vibrations at 1,474 and $740 \mathrm{~cm}^{-1}$. The bands at 1400, 1271, 1010, 933, 740, 614 and $431 \mathrm{~cm}^{-1}$ are assigned to benzimidazole ring vibrations. The $v_{\mathrm{C}-\mathrm{N}}$ and $\delta_{\mathrm{N}-\mathrm{H}}$ of the benzimidazole moiety appear around $1,318 \mathrm{~cm}^{-1}$. A band at $1,046 \mathrm{~cm}^{-1}$ may be assigned to $v_{\mathrm{C}-\mathrm{N}}$ of the aminophenyl group. The $\mathrm{NH}_{2}$ out of plane bending is observed at $855 \mathrm{~cm}^{-1}$. The bands around 766 and $692 \mathrm{~cm}^{-1}$ may be ascribed to $\mathrm{NH}$ out of plane bending vibrations. The assignments are tentative and are based on earlier assignments for similar groupings [23-25].

The infrared spectra of the neat complexes are similar to those of the ligand spectra. The $v_{\mathrm{N}-\mathrm{H}}$ of $\mathrm{NH}_{2}$ occurs as a
Table 2 Thermogravimetric analysis data of encapsulated AmPhBzlH complexes

\begin{tabular}{|c|c|c|c|c|}
\hline Sl. No. & Complex & $\begin{array}{l}\text { Temperature } \\
\text { range }\left({ }^{\circ} \mathrm{C}\right)\end{array}$ & $\begin{array}{l}\text { Weight } \\
\text { loss (\%) }\end{array}$ & Group lost \\
\hline \multirow[t]{3}{*}{1} & \multirow[t]{3}{*}[\mathrm{Co}(\mathrm{AmPhBzlH})]{$-\mathrm{Y}$} & $60-160$ & 14.0 & $n \mathrm{H}_{2} \mathrm{O}$ \\
\hline & & $160-340$ & 7.5 & $\mathrm{H}_{2} \mathrm{O}+\mathrm{Cl}^{-}$ \\
\hline & & $340-640$ & 1.5 & $\mathrm{~L}$ \\
\hline \multirow[t]{3}{*}{2} & \multirow[t]{3}{*}[\mathrm{Co}(\mathrm{AmPhBzlH})]{$-\mathrm{ZSM}-5$} & $45-140$ & 2.5 & $n \mathrm{H}_{2} \mathrm{O}$ \\
\hline & & $140-360$ & 2.5 & $\mathrm{H}_{2} \mathrm{O}+\mathrm{Cl}^{-}$ \\
\hline & & $360-780$ & 2.5 & $\mathrm{~L}$ \\
\hline \multirow[t]{3}{*}{3} & \multirow[t]{3}{*}[\mathrm{Cu}(\mathrm{AmPhBzlH})]{$-\mathrm{Y}$} & $45-154$ & 16.30 & $n \mathrm{H}_{2} \mathrm{O}$ \\
\hline & & $154-467$ & 7.39 & $\mathrm{H}_{2} \mathrm{O}+\mathrm{Cl}^{-}$ \\
\hline & & $467-764$ & 1.74 & $\mathrm{~L}$ \\
\hline \multirow[t]{3}{*}{4} & \multirow[t]{3}{*}[\mathrm{Cu}(\mathrm{AmPhBzlH})]{$-\mathrm{ZSM}-5$} & $39-100$ & 6.12 & $n \mathrm{H}_{2} \mathrm{O}$ \\
\hline & & $100-555$ & 5.43 & $\mathrm{H}_{2} \mathrm{O}+\mathrm{Cl}^{-}$ \\
\hline & & $555-800$ & 2.3 & $\mathrm{~L}$ \\
\hline \multirow[t]{3}{*}{5} & \multirow[t]{3}{*}[\mathrm{Zn}(\mathrm{AmPhBzlH})]{$-\mathrm{Y}$} & $42-154$ & 9.36 & $n \mathrm{H}_{2} \mathrm{O}$ \\
\hline & & $154-304$ & 13.35 & $\mathrm{H}_{2} \mathrm{O}+\mathrm{Cl}^{-}$ \\
\hline & & $304-800$ & 7.35 & $\mathrm{~L}$ \\
\hline \multirow[t]{3}{*}{6} & \multirow[t]{3}{*}{ [Zn(AmPhBzlH)]-ZSM-5 } & $45-106$ & 6.07 & $n \mathrm{H}_{2} \mathrm{O}$ \\
\hline & & $106-363$ & 3.82 & $\mathrm{H}_{2} \mathrm{O}+\mathrm{Cl}^{-}$ \\
\hline & & $363-796$ & 3.15 & $\mathrm{~L}$ \\
\hline
\end{tabular}




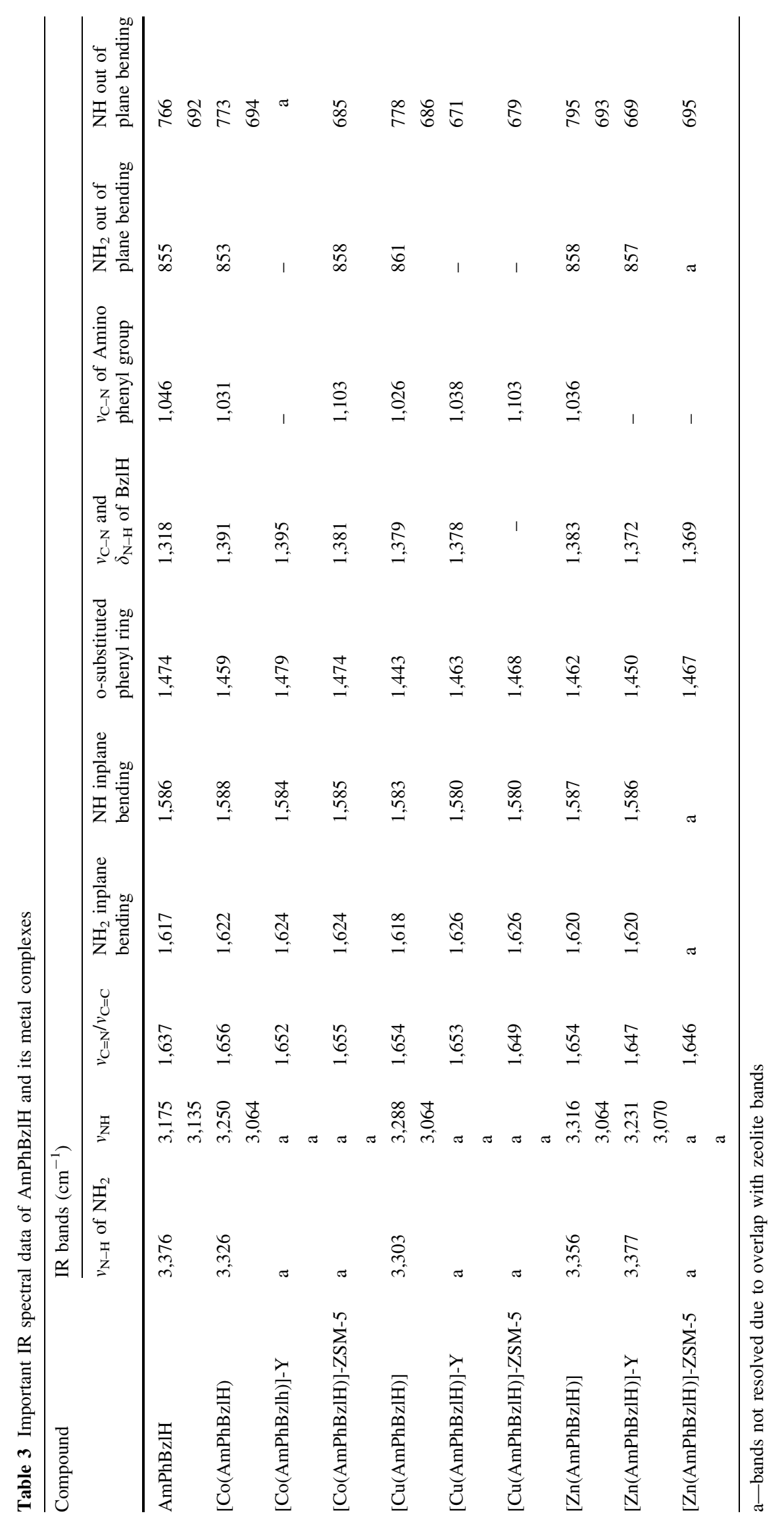


weak peak in the range $3,356-3,284 \mathrm{~cm}^{-1}$. This shift of $v_{\mathrm{N}-\mathrm{H}}$ of $\mathrm{NH}_{2}$ in the complex compared to that of the ligand indicates its coordination to the metal. The $v_{\mathrm{NH}}$ of benzimidazole appears as a split broad band in the range 3,316$3,070 \mathrm{~cm}^{-1}$. The bending mode of $\mathrm{NH}_{2}$ has also shifted from $1,617 \mathrm{~cm}^{-1}$ in the ligand to $1,618-1,624 \mathrm{~cm}^{-1}$ in the complex. The $v_{\mathrm{C}=\mathrm{N}}$ in the complex is observed around $1,652-1,654 \mathrm{~cm}^{-1}$. The $v_{\mathrm{C}-\mathrm{N}}$ of the aminophenyl group seems to have gained intensity and has shifted to lower frequency $1,026-1,044 \mathrm{~cm}^{-1}$. The $\mathrm{N}-\mathrm{H}$ out of plane bending vibrations occurring at 766 and $692 \mathrm{~cm}^{-1}$ for the ligand appear to exhibit minor shifts in the complexes. Thus, several of these bands also show appreciable shifts when compared to their positions in the ligand spectrum due to coordination of the ligand to metal.

The IR spectrum of metal encapsulated zeolite is almost the same as that of the parent zeolite which shows that the basic zeolite structure remains the same on metal exchange [26-28]. Some bands observed in the neat complex spectrum are not seen in the spectrum of the encapsulated complex as they are masked by the strong absorption bands of the zeolite. But still the formation of complex inside the cavities are observed by the different bands which are assigned clearly by comparing with the spectra of the ligand and neat complexes (Table 3). We have not observed any broadening and shift in the positions of the zeolite bands, which indicates that no change has occurred in the zeolite framework. This clearly indicates that the metal complexes fit well within the cavities of the zeolites.

\subsection{Electronic spectral studies}

The electronic spectral data of ligand, neat and encapsulated complexes recorded are given in Table 4. The location and coordination taken up by the metal cations in the complexes within the zeolite cavities is well understood by the electronic spectral data of the complexes. The solid state electronic spectra of the ligand, neat and encapsulated complexes of $\mathrm{AmPhBzlH}$ were taken by using $\mathrm{BaSO}_{4}$. Due to the low intensity of the observed bands in the encapsulated complexes, some uncertainties arise in the detailed assignments of the bands. The bands at higher frequencies can be due to charge transfer transitions, which are evident from the high intensity of these bands.

The Co[AmPhBzlH] complex shows three bands in the region 600 to $700 \mathrm{~nm}$. The band at around $637 \mathrm{~nm}$ assigned to $\mathrm{d}-\mathrm{d}$ transition is typical of tetrahedral $\mathrm{Co}$ (II) complexes [29]. Similar observations were made in case of encapsulated complexes which suggest that the cobalt complex with tetrahedral geometry were formed inside the zeolite cavities.

The neat $\mathrm{Cu}$ (II) complex shows three bands at 380,481 and $626 \mathrm{~nm}$ which are assigned to charge transfer and $\mathrm{d}-\mathrm{d}$
Table 4 Electronic spectral data of AmPhBzlH and its metal complexes

\begin{tabular}{|c|c|c|c|}
\hline Sl. No. & Compound & $\begin{array}{l}\lambda_{\max } \\
(\mathrm{nm})\end{array}$ & Tentative assignments \\
\hline 1 & {$[\mathrm{Co}(\mathrm{AmPhBzlH})]$} & $\begin{array}{l}418 \\
595 \\
637 \\
684\end{array}$ & $\begin{array}{l}\text { Charge transfer } \\
\text { d-d } \\
\text { d-d } \\
\text { d-d }\end{array}$ \\
\hline 2 & {$[\mathrm{Co}(\mathrm{AmPhBzlH})]-\mathrm{Y}$} & $\begin{array}{l}380 \\
514 \\
685\end{array}$ & $\begin{array}{l}\text { Charge transfer } \\
\text { d-d } \\
d-d\end{array}$ \\
\hline 3 & {$[\mathrm{Co}(\mathrm{AmPhBzlH})]-\mathrm{ZSM}-5$} & $\begin{array}{l}377 \\
478\end{array}$ & $\begin{array}{l}\text { Charge transfer } \\
\text { d-d }\end{array}$ \\
\hline 4 & {$[\mathrm{Cu}(\mathrm{AmPhBzlH})]$} & $\begin{array}{l}380 \\
481 \\
626\end{array}$ & $\begin{array}{l}\text { Charge transfer } \\
\text { d-d } \\
d-d\end{array}$ \\
\hline 5 & {$[\mathrm{Cu}(\mathrm{AmPhBzlH})]-\mathrm{Y}$} & $\begin{array}{l}371 \\
478 \\
769\end{array}$ & $\begin{array}{l}\text { Charge transfer } \\
\text { d-d } \\
d-d\end{array}$ \\
\hline 6 & {$[\mathrm{Cu}(\mathrm{AmPhBzlH})]-\mathrm{ZSM}-5$} & $\begin{array}{l}364 \\
476 \\
589\end{array}$ & $\begin{array}{l}\text { Charge transfer } \\
\text { d-d } \\
d-d\end{array}$ \\
\hline 7 & {$[\mathrm{Zn}(\mathrm{AmPhBzlH})]$} & 363 & Charge transfer \\
\hline 8 & {$[\mathrm{Zn}(\mathrm{AmPhBzlH})]-\mathrm{Y}$} & 372 & Charge transfer \\
\hline 9 & {$[\mathrm{Zn}(\mathrm{AmPhBzlH})]-\mathrm{ZSM}-5$} & 374 & Charge transfer \\
\hline
\end{tabular}

transitions. A broad band observed around $626 \mathrm{~nm}$ in the neat $\mathrm{Cu}$ (II) complex is assigned to the ${ }^{2} \mathrm{~B}_{1 \mathrm{~g}} \rightarrow{ }^{2} \mathrm{~A}_{1 \mathrm{~g}}$ transition. In the case of encapsulated complexes also, similar observations were made and assigned to charge transfer and $\mathrm{d}-\mathrm{d}$ transitions. The transitions observed support a square planar geometry for the copper complex formed inside the zeolite cavities [30].

The dark yellow coloured neat and encapsulated complexes of $\mathrm{Zn}$ (II) show a charge-transfer transition along with the $\pi-\pi^{*}$ transition of benzimidazole moiety. As expected no bands due to $\mathrm{d}-\mathrm{d}$ transitions are observed for neat and encapsulated $\mathrm{Zn}$ (II) complexes and charge transfer transition was observed in the range $363-374 \mathrm{~nm}$. It was reported that $\mathrm{Zn}$ (II) neat complex has a tetrahedral configuration which is realized by participation of the imidazole nitrogen of two organic ligand molecules and two nitrate anions, typical for these classes of organic ligands [31, 32].

\subsection{EPR spectra}

The EPR spectra of $\mathrm{Cu}(\mathrm{II})$ encapsulated complexes were recorded at room temperature using TCNE as reference. The spectra obtained are as shown in Fig. 2. 


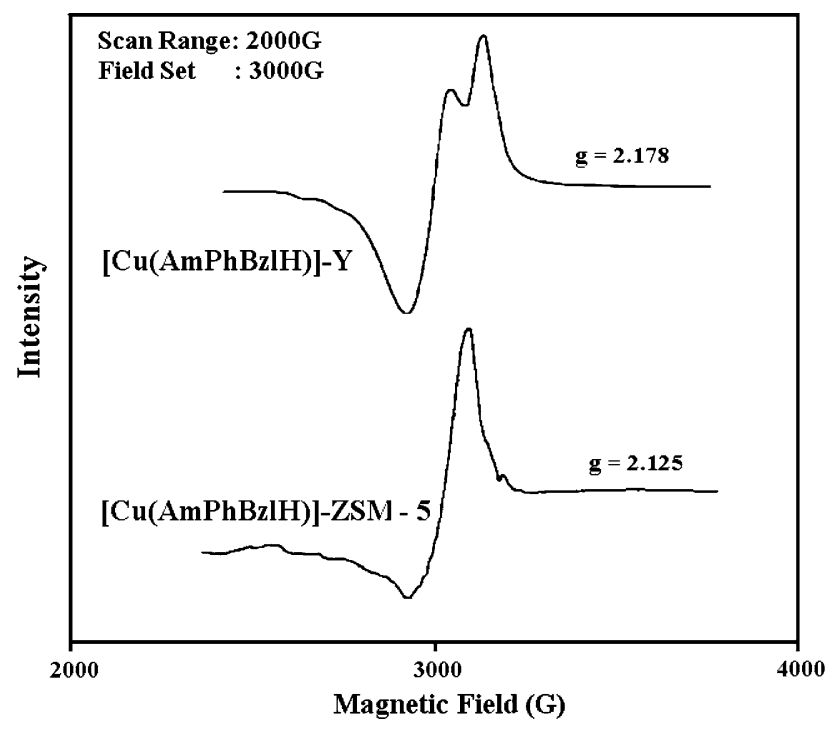

Fig. 2 EPR spectrum of $[\mathrm{Cu}(\mathrm{AmPhBzlH})]-\mathrm{Y}$ and $[\mathrm{Cu}(\mathrm{AmPhBzlH})]$ ZSM-5 complexes

For copper complexes the $\mathrm{g}$ values are found to be 2.18 and 2.12 and are $<2.3$ indicating that the complexes possesses considerable covalent character in the metal ligand bond [31]. The interactions of the zeolite framework with the encapsulated complex could induce some distortions in the expected structure.

\subsection{Catalytic activity studies}

\subsubsection{Decomposition of $\mathrm{H}_{2} \mathrm{O}_{2}$}

The catalytic activity for the decomposition of $\mathrm{H}_{2} \mathrm{O}_{2}$ with the encapsulated complexes was studied. The quantity of $\mathrm{H}_{2} \mathrm{O}_{2}$ that reacted and the turn over frequency (TOF) at two different time intervals ( 1 and $2 \mathrm{~h}$ ) were measured. The results tabulated in Table 5, show that the decomposition of $\mathrm{H}_{2} \mathrm{O}_{2}$ is slow initially but increases with time. This is due to the fact that the encapsulated complex used requires relatively longer time to exhibit maximum catalytic activity as number of metal centers is less compared to that of the neat complex. Hence increasing the duration of the reaction is a very effective way of carrying out the reaction with $\mathrm{H}_{2} \mathrm{O}_{2}$ as the source of oxygen.

\subsubsection{Hydroxylation of phenol}

The catalytic hydroxylation of phenol using different encapsulated complexes was studied as a function of time using the aqueous $\mathrm{H}_{2} \mathrm{O}_{2}$ solution as the oxidant and acetonitrile as the solvent. Catechol and hydroquinone were obtained as the major products, as shown in Scheme 2. No minor products were detected in GC under the conditions employed here.

The reaction was carried out for $6 \mathrm{~h}$ with the optimized condition $\left(0.025 \mathrm{~mol}\right.$ phenol, $4 \mathrm{ml} \mathrm{H}_{2} \mathrm{O}_{2}, 6.0$ mmol catalyst in $2 \mathrm{ml}$ of acetonitrile at $80{ }^{\circ} \mathrm{C}$ ) for all catalysts. The effect of different catalysts on the percentage conversion of phenol and percentage formation oxidation products of catechol and hydroquinone is represented in Fig. 3. It clearly indicates that maximum phenol conversion is observed with increase in reaction time for all catalysts.

The maximum conversion of phenol obtained is with $[\mathrm{Cu}(\mathrm{AmPhBzlH})]-Y$. The order of catalytic activity for hydroxylation of phenol is found to be as follows $[\mathrm{Cu}(\mathrm{AmPhBzlH})]-\mathrm{Y} \quad(56 \%)>[\mathrm{Cu}(\mathrm{AmPhBzlH})]-\mathrm{ZSM}-5$ $(54 \%)>[\mathrm{Co}(\mathrm{AmPhBzlH})]-\mathrm{Y}(52 \%)>[\mathrm{Co}(\mathrm{AmPhBzlH})]-$ ZSM-5 $(51 \%)>[\mathrm{Zn}(\mathrm{AmPhBzlH})]-\mathrm{Y}(49 \%)>[\mathrm{Zn}(\mathrm{AmP}-$ $\mathrm{hBzlH})]-Z S M-5(48 \%)$ after $6 \mathrm{~h}$ of reaction time.

A maximum conversion of $46 \%$ to catechol and $10 \%$ to hydroquinone formation was obtained with $[\mathrm{Cu}(\mathrm{AmP}-$ $\mathrm{hBzlH})]-\mathrm{Y}$ as catalyst. The order of catechol formation with different catalysts is as follows: $[\mathrm{Cu}(\mathrm{AmPhBzlH})]-$ $\mathrm{Y}>[\mathrm{Zn}(\mathrm{AmPhBzlH})]-\mathrm{Y}>[\mathrm{Zn}(\mathrm{AmPhBzlH})]-\mathrm{ZSM}-5>$



Scheme 2 Hydroxylation of phenol
Table 5 Percentage decomposition of $\mathrm{H}_{2} \mathrm{O}_{2}$

TOF-moles of the substrate converted per mole of the metal (in the solid catalyst) per hour

\begin{tabular}{|c|c|c|c|c|}
\hline \multirow[t]{2}{*}{ Catalyst $^{\mathrm{a}}$} & \multicolumn{2}{|l|}{ After $1 \mathrm{~h}$} & \multicolumn{2}{|l|}{ After $2 \mathrm{~h}$} \\
\hline & $\mathrm{H}_{2} \mathrm{O}_{2}$ reacted $(\%)$ & $\operatorname{TOF}^{\mathrm{b}}\left(\mathrm{h}^{-1}\right)^{\mathrm{b}}$ & $\mathrm{H}_{2} \mathrm{O}_{2}$ reacted $(\%)$ & TOF $\left(h^{-1}\right)^{b}$ \\
\hline$[\mathrm{Co}(\mathrm{AmPhBzlH}))]-\mathrm{Y}$ & 0.33 & 192.78 & 1.33 & 385.59 \\
\hline$[\mathrm{Co}(\mathrm{AmPhBzlH}))]-\mathrm{ZSM}-5$ & 13.02 & 21.58 & 17.93 & 14.868 \\
\hline$[\mathrm{Cu}(\mathrm{AmPhBzlH}))]-\mathrm{Y}$ & 0.25 & 50.6 & 1.92 & 194.0 \\
\hline$[\mathrm{Cu}(\mathrm{AmPhBzlH}))]-\mathrm{ZSM}-5$ & 74.77 & 148.92 & 98.0 & 100.06 \\
\hline$[\mathrm{Zn}(\mathrm{AmPhBzlH}))]-\mathrm{Y}$ & 0.83 & 201.43 & 2.42 & 584.15 \\
\hline$[\mathrm{Zn}(\mathrm{AmPhBzlH}))]-\mathrm{ZSM}-5$ & 5.34 & 2.73 & 22.36 & 5.71 \\
\hline
\end{tabular}






Fig. 3 Comparison of phenol, catechol and hydroquinone produced with zeolite encapsulated metal complexes of AmPhBzlH

$[\mathrm{Co}(\mathrm{AmPhBzlH})]-\mathrm{Y}>[\mathrm{Cu}(\mathrm{AmPhBzlH})]-\mathrm{ZSM}-5>[\mathrm{Co}$ (AmPhBzlH)]-ZSM-5.

The hydroquinone formation for different catalysts employed follows the order as below; $[\mathrm{Cu}(\mathrm{AmPhBzl})]-$ ZSM-5 > [Co(AmPhBzlH) $]-Z S M-5>[C o(A m P h B z l H)]-$ $\mathrm{Y}>[\mathrm{Zn}(\mathrm{AmPhBzlH})]-\mathrm{ZSM}-5>[\mathrm{Cu}(\mathrm{AmPhBzlH})]-\mathrm{Y}>$ $[\mathrm{Zn}(\mathrm{AmPhBzlH})]-\mathrm{Y}$. For all the catalysts, the selectivity is much more for catechol than hydroquinone.

\subsection{Recycling test}

Phenol hydroxylation reaction was carried out by using recycled catalyst for the zeolite encapsulated AmPhBzlH catalysts. The data are given in Table 6 .

After the completion of the reaction with fresh catalyst, the catalyst was filtered, washed with acetone and then dried at $110{ }^{\circ} \mathrm{C}$. Then the recycled catalyst was used again to test its catalytic activity for phenol hydroxylation by conducting the reaction under the same reaction conditions which was optimized for a particular ligand as explained earlier. A comparison of the percentage conversion of phenol for the fresh and the recycled catalysts shows that

Table 6 Phenol hydroxylation reaction with fresh and recycled catalyst

\begin{tabular}{llll}
\hline Sl. No. & Catalyst used & \multicolumn{2}{c}{ Phenol conversion $(\%)$} \\
\cline { 3 - 4 } & & Fresh & Recycled \\
\hline 1 & {$[\mathrm{Co}($ AmPhBzl)]-Y } & 52.04 & 50.76 \\
2 & {$[\mathrm{Cu}(\mathrm{AmPhBzl})]-\mathrm{Y}$} & 55.63 & 52.86 \\
3 & {$[\mathrm{Zn}(\mathrm{AmPhBzl})]-\mathrm{Y}$} & 49.20 & 46.09 \\
4 & {$[\mathrm{Co}(\mathrm{AmPhBzl})]-Z S M-5$} & 51.42 & 49.03 \\
5 & {$[\mathrm{Cu}(\mathrm{AmPhBzl})]-Z S M-5$} & 54.27 & 49.76 \\
6 & {$[\mathrm{Zn}(\mathrm{AmPhBzl})]-Z S M-5$} & 48.53 & 47.24 \\
\hline
\end{tabular}

there is small decrease in the activity of recycled catalysts may be because of the presence of adsorbed molecules. But the selectivity for the product formation remains almost unaltered.

\section{Conclusions}

$\mathrm{Co}(\mathrm{II}), \mathrm{Cu}(\mathrm{II})$ and $\mathrm{Zn}(\mathrm{II})$ complexes of 2-(o-aminophenyl)benzimidazole have been encapsulated in the super cages of zeolite-Y and ZSM-5. Chemical analysis, surface area measurements, spectroscopic studies, XRD patterns and thermal analysis gave clear evidence for their encapsulation. This was confirmed by running a blank reaction. No leaching of metal ions was detected in the solution. The influence of different factors such as the amount of oxidant, catalyst, temperature, volume and type of solvents of the reaction mixture was studied and these factors show different catalytic activities in the decomposition of $\mathrm{H}_{2} \mathrm{O}_{2}$ and hydroxylation of phenol. [Cu(AmPhBzlH)]-Y shows maximum phenol conversion with $82 \%$ selectivity for catechol formation. The percent selectivity for the formation of catechol is always higher for all the types of catalysts prepared than for hydroquinone. Comparable IR and XRD patterns of fresh and used encapsulated catalysts suggest that these can be used further for catalytic study.

Acknowledgments The authors gratefully acknowledge the support received from Bangalore University, Bangalore for carrying out this work and BIT, Bangalore, SAIF, Kochi, Kerala, SAIF, IIT, Bombay and Department of physics, IISc, Bangalore for the analysis.

\section{References}

1. M. Salavati-Niasari, S. Shafaie-Arani, M. Reza Ganjali, P. Norouzi, Trans. Metal. Chem. 31, 964 (2006)

2. C. Ratnasamy, A. Murugkar, S. Padhye, S.A. Pardhy, Indian J. Chem. 35, 1-3 (1996)

3. K.K. Fodor, G.A. Sebastiaan, R.A. Sheldon, Enatiomer 4, 497 (1999)

4. G.J. Hutchings, Chem. Commun. 301 (1999)

5. J.S. Rafelt, J.H. Clark, Catal. Today 57, 3 (2000)

6. R.A. Sheldon, I.W.C.E. Arends, A. Dijksman, Catal. Today 57, 157 (2000)

7. R.A. Sheldon, R.A. Vansanten, Catalytic Oxidation: Principles and Applications (World Scientific, Singapore, 1995)

8. R. Raja, P. Ratnasamy, Stud. Surf. Sci. Catal. 101, 181 (1996)

9. C.R. Jacob, S.P. Varkey, P. Ratnasamy, Microporous Mesoporous Mat. 22, 465 (1998)

10. S. Seelan, A.K. Sinha, D. Srinivas, S. Sivasanker, Bull. Catal. Soc. India 1, 29 (2002)

11. M.R. Maurya, M. Kumar, S.J.J. Titinchi, H.Sl. Abbo, S. Chand, Catal. Lett. 86, 97 (2003)

12. B.P. Nethravathi, K.N. Mahendra, J. Porous. Mater. 17, 107 (2010)

13. M. Taramasso, G. Perego, B. Notari, U.S. Patent 4,410,501 (1983) to sanamprogetti, M. Taramasso, G. Manara, B. Fattore, B. Notari, U.S. Patent 4,666,692 (1987) to sanamprogetti 
14. Q. Yang, C. Li, S. Yuan, J. Li, P. Ying, Q. Xin, W. Shi, J. Catal. 183, 128 (1999)

15. D.D. Perrin, W.L.F. Armanego, D.R. Perrin, Purification of Laboratory Chemicals (Pergamon Press, Oxford, 1966)

16. D.W. Hein, R.J. Alheim, J.J. Leavitt, J. Am. Chem. Soc. 79, 427 (1957)

17. V. Rives, A. Dubey, S. Kannan, Phys. Chem. Chem. Phys. 3, $4826(2001)$

18. J. Bassett, R.C. Denney, G.H. Jeffery, J. Mendham, Vogel's Textbook of Quantitative Inorganic Analysis, 4th edn. (Longman Scientific and Technical, London, 1978)

19. C. Subrahmanyam, B. Louis, B. Viswanathan, A. Renken, T.K. Varadarajan, Bull. Catal. Soc. India, 3 (2004)

20. N. Shashikala, E.G. Leelamani, G.K.N. Reddy, Indian J. Chem. 21A, 743 (1982)

21. K.J. Balkus Jr., A.G. Gabrielov, J. Incl. Phenom. Mol. Recogn. Chem. 21, 159 (1995)

22. R. Raja, P. Ratnasamy, J. Catal. 170, 244 (1997)

23. N. Shashikala, Transition metal complexes with substituted benzimidazoles, Ph.D Thesis, Bangalore University, 1984
24. C. Ratnasamy, A. Murugkar, S. Padhye, S.A. Pardhy, Indian J. Chem. 35, 1 (1996)

25. K. Nakanishi, P.H. Solomon, Infrared Absorption Spectroscopy (Holden- Day Inc., Sydney, 1977)

26. L.J. Bellamy, The Infrared Spectra of Complex Molecules (Wiley, New York, 1962)

27. E.M. Flanigen, Zeolite Chemistry and Catalysis, ACS Monograph, American Chemical Society, Washington DC (1976)

28. P.A. Jacobs, H.K. Beyer, J. Valyon, Zeolites 1, 161 (1981)

29. G. Krishnamurthy, Reactions of transition metal ions with substituted benzimidazoles and their catalytic activity, Ph.D Thesis, Bangalore University, 2005

30. S. Konstantinovic, C. Radovanovic, Z. Capic, V. Basic, J. Serb. Chem. Soc. 68, 641 (2003)

31. K. Rama Krishna Reddy, synthesis and characterisation of metal complexes with ligands containing $\mathrm{O}, \mathrm{N}$ and $\mathrm{S}$ donor sites and the study of biological activities of these complexes, $\mathrm{Ph}$. D Thesis, Bangalore University, 2008

32. S.O. Podunavac-Kuzmanovic, L.S. Vojinovic, APTEFF 34, 119 (2003) 